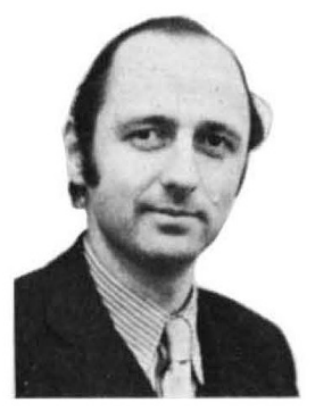

Within a week of Parliament giving the go-ahead for the world's largest nuclear fuel reprocessing plant at Windscale, Cumbria, Britain and Japan signed a $£ 500$ million contract which will help pay for the plant and give Japan the right to transport 1600 tonnes of spent fuel to the UK. The plant is not yet built, however, and opposition to it among an increasing number of MPs has been both strong and vocal. Here Nigel Forman, MP, Joint Secretary of the Conservative Back Bench Energy Committee, voices his own disquiet

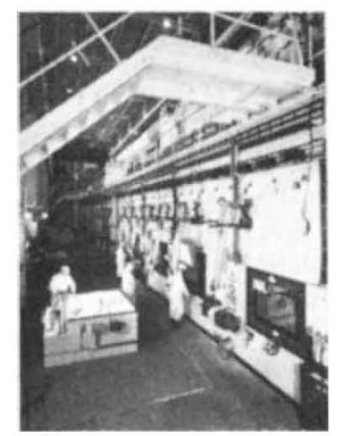

\title{
The Windscale error
}

$\mathbf{O}^{\mathrm{N}}$ N Monday 15 May 1978 at $10 \mathrm{pm}$ the House of Commons decided by a vote of 224 to 80 to give the goahead necessary for the development of the planned Thermal Oxide Reprocessing Plant (THORP) at Windscale. The issues involved were both complicated and controversial, but the decision itself was clear-cut and of lasting significance. It set the seal on many months of confused and sometimes angry debate, but it also signified a new degree of nuclear commitment for this country.

At the beginning of his Report on the Windscale Inquiry, $\mathbf{M r}$ Justice Parker posed three key questions:

- Should oxide fuel from UK reactors be reprocessed in this country at all;

- if so, should such reprocessing be carried on at Windscale;

- if so, should the plant be about double the estimated size required to handle UK oxide fuels, so that the spare capacity could be used for reprocessing foreign spent fuel?

These were not really the right questions to ask. The key questions should have been:

- should British Nuclear Fuels Ltd (BNFL) be allowed to build an 'economic' THORP at Windscale;

- if this was not feasible, should it be allowed to build an "uneconomic" plant;

- are there in any case such strong objections to reprocessing on any basis that it should be delayed or even foregone?

The idea of building an 'economic' THORP at Windscale is based upon BNFL's expectation that there will be about $1600 \mathrm{~m}$ worth of foreign business which it will be able to exploit on a cost plus $25 \%$ basis in the early 1990 's and beyond. It is also dependent upon the assumption that BNFL will get a continuous flow of foreign orders on a comparable basis beyond those which are already in prospect. The economic attractions of THORP can be summarised as getting the Japanese and other foreign customers to sub-

Nigel Forman is the author of Towards $a$ more Conservative Energy Policy, Conservative Policy Centre, London 1977 sidise the capital costs of the plant, securing some additional foreign currency over a period when we should not need it quite so much as in recent years, and spreading the costs of our own reprocessing programme over a larger through-put (up to a planned maximum capacity of 1200 tonnes per annum) so as to secure lower unit costs and hence less of a burden from this source on electricity prices.

If these assumptions prove to be reliable-and we should bear in mind that it was BNFL which argued that they will be-the main question under this heading should have been whether or not the assumed economic benefits of THORP are likely to prove sufficiently reliable and attractive to outweigh the non-economic costs and disadvantages. In Para 9.17 of his Report, Mr Justice Parker took the view that "it is as yet too early to reach any final conclusions on the economic position". The proper verdict, supported by the findings of the recent MITRE Report, ought, therefore, to have been the Scottish judicial formula 'not proven'.

However, there is also an argument for building an 'uneconomic' plant. It is based upon the contentions that we already have to reprocess the spent fuel from our own Magnox and AGR stations, that reprocessing is the best available technique of waste management, and that doing it under high standard controlled conditions at Windscale will reduce rather than increase the risks of further nuclear proliferation in the world.

Powerful though it appears to be, such an argument is based upon a number of questionable assumptions. First, there is the assumption that BNFL needs a new plant with the capacity of THORP to deal with the spent fuel arising from our existing nuclear programme. Second, there is the assumption that it is necessarily preferable to reprocess rather than store the spent fuel. Third, there is the assumption that BNFL is wise to reject even more radical alternatives, such as the Linear Accelerator Breeder which would not involve either enrich- ment or reprocessing. Finally, there is the assumption that the demonstration effect of going ahead with THORP will discourage rather than encourage others to do likewise.

Of course there is as yet no consensus of international expert opinion on these issues. For example, studies recently completed by the Swedish Atomic Forum suggest that spent fuel could be stored safely underground for at least 5,000 years in specially designed ceramic or copper canisters. This contrasts strongly with the views of BNFL and the UK Atomic Energy Authority, summarised in Para 8.14 of the Parker Report, which were that zircaloy fuel might be stored for up to 20 years and still remain suitable for handling and reprocessing, that it would be imprudent to store substantial quantities of stainless steel clad fuel in ponds for more 10 years, and that further evidence was required before present plans for early reprocessing could prudently be modified. Yet would anyone seriosly expect BNFL - one of the parties to the Windscale dispute-to have come to a technical conclusion which was anything other than a vindication of its own practice?

The real truth about the storage/ reprocessing debate is that there is a whole range of possibilities which is currently being reviewed within the International Fuel Cycle Evaluation Programme (INFCE), and that the attitude of each of the major parties depends most upon the strategic choices first made at the outset of its nuclear programme-in our case in favour of reprocessing to extract plutonium for our independent nuclear weapons programme in the late 1940's and early 1950's.

Then there remains legitimate doubt about the vitrification process, with which Mr Justice Parker said he was satisfied in Para 8.30 of his Report and which he predicted would succeed because it had to succeed. What a curious, but unfortunate, judicial syllogism! There is also persistent doubt surrounding the preferred method of final disposal for the highly 
active wastes, on which $\mathrm{Mr}$ Justice Parker's simple but bland comment in Para 8.31 was that "a final solution to the problems of disposal has not yet been found". Of course, he accepted in Para 8.32 that there should be no commitment to a large programme of nuclear fission power in this country until these and other waste disposal problems had been solved. It was readily apparent, however, that the Judge accepted the Government's view that the building of THORP does not necessarily imply such a commitment.

Yet this begs the question: what is a large nuclear programme in this context? The Government is now projecting $9.4 \mathrm{GW}$ of net installed nuclear capacity in the UK in 1985 and the recent Energy Policy Green Paper envisaged perhaps $40 \mathrm{GW}$ in the year 2000. Since THORP will not be fully on stream until the early 1990's and since by then we may well have some $20 \mathrm{GW}$ of installed nuclear capacity in the UK meeting perhaps $30 \%$ of our electricity needs, at what point will the Government admit to having a large nuclear fission programme? The answer, it seems, is always just far enough into the future to be conveniently safe from falling foul of any inconvenient conditions which may be laid down by Royal Commissions or Judicial Inquiries.

Above all, there remains the serious doubt about Mr Justice Parker's excessively legalistic view of the vital nonproliferation issue. The fact is that it is political attitudes which are decisive in this matter and they are moving all the time towards a tougher more uncompromising position, not only within the US Administration, but also within the special forum of the Nuclear Suppliers' Group. The decision to go ahead with THORP thus flies in the face of American policy and is a calculated snub to most of the parties involved in the INFCE discussions. In this context, Mr Justice Parker was quite simply wrong in Para 6.23 of his Report when he argued that the building of THORP itself would not be counter to US policy.

The ultimate question, however, is whether or not there are such strong objections to reprocessing that the decision to build THORP should have been delayed or foregone. The fundamental argument for THORP is that we know how to do it and that if we had decided not to do it, others would have gone ahead, scooping the available foreign business in the process. It is also based on certain important energy policy assumptions which were not made very explicit in the Parker Report. These include the assumption that new reprocessing capacity of this kind will be a necessary but not a sufficient condition for series ordering of fast reactors in this country-at any rate beyond the ninth such reactor. This in turn is based upon the assumption that we in the UK will have to depend heavily upon nuclear electricity for our energy needs in the 1990's and beyond, and that in such a situation we ought to minimise our dependence on foreign resources and technology.

In fact, Mr Justice Parker himself went further, making the assertion (Para 8.37) that "the only prudent course is to adopt a strategy which will give the greatest assurance that, no matter how the variables change, the energy needed to support an acceptable society can be provided" (the use of italics is mine). Not content with this, the Judge went on to argue in Para 8.40 that we should not divert available. resources to energy savings and alternative energy sources "to an extent which would prejudice a large scale reliance on nuclear power".

Furthermore, it may be wondered why $\mathrm{Mr}$ Justice Parker and others seem to assume that considerations of resource and technology independence will appeal only to us in the UK; or why it is regarded as more or less inevitable that we shall have to reprocess a total of 6,000 tonnes of spent fuel from UK reactors alone by the year 2000; or why it is assumed that a refurbishing of Building 204/205 at the existing Windscale plant would not be capable of handling our own spent fuel requirements? The simple answer to such questions is that such assumptions were made in the Report because they constituted the bedrock of BNFL's evidence to $\mathbf{M r}$ Justice Parker at the Inquiry and because that was the evidence which he chose to accept in preference to that of the objectors.

However, it should be asked whether the Judge was wise to have based his crucial assumptions so heavily upon BNFL's so-called realistic forecasts, when their origin was in fact none other than the planners in the Department of Energy and the Atomic Energy Authority. And was it really wise for the Judge to have dismissed the alternative views of reprocessing on the grounds that they were "of recent origin" (Para 3.1) or that they are sustained by public anxieties which he chose to describe as "needless", "without foundation" and even "irrational and misplaced" (Para 2.1)? This is hardly the sort of language that people expected to find in an impartial, judicial Report.

The Windscale decision ought not to have been seen as a choice between the risks of reprocessing and the risks of energy shortage by relying solely on non-nuclear means, which was how $\mathbf{M r}$ Tony Benn expressed it in winding up the Debate on 15 May. Many of those who retain serious doubts about
THORP are not advocating the elimination of what the Secretary of State described as the "nuclear component" in our energy mix. It would be possible to have a nuclear component without THORP and it would even be possible to have it without reprocessing at all. False polarities in the debate have not assisted clarity of thought or decision.

The Government's case for proceeding with THORP was essentially: - that the nuclear component is necessary for UK energy policy;

- that THORP is necessary for that nuclear component to develop properly; and

- that the objections raised at the Inquiry did not justify postponement or cancellation.

It is clearly possible to accept the first argument without necessarily accepting the second and third.

In the first place, nothing would really have been lost by postponing a decision until the outcome of the INFCE discussions is known in about 18 months time. Indeed, BNFL itself is on record in Para 8.6 of the Parker Report to the effect that a start on THORP could have been delayed for up to five years without any irreparable harm being done.

Secondly, since the decision involved a project which will not be fully operational until the early 1990's and since the Japanese spent fuel, for example, will have to be stored in any case for some years before it is put through THORP, there would have been little or nothing to lose from spending a bit more time in serious international investigation of all the possible alternative fuel cycles, making further vigorous efforts to stuff the genie of nuclear proliferation back into a safer bottle, and giving further sober consideration to the new more conservative energy forecasts upon which all our future plans should now be based. After all, even the greatest energy experts are still relatively low on the learning curve about the full potential of safer, cheaper, alternative energy futures.

Of course, a counsel of delay would be irresponsible if it were not based on the assumption that the best possible use would have been made of the breathing space thus gained to investigate all the available alternatives to THORP, and that further rigorous conditions would have been imposed on the development had it been given the go-ahead in the end. However, from a responsible and even ethical point of view a decision to delay would have provided a rare opportunity in the developed world to show that we are capable of moving from the politics of prescription to the politics of proscription. That would have been a signal of hope for mankind. 